Tema: $1^{\circ}$ Workshop de tratamentos de superfícies de ligas resistentes à corrosão

\title{
AVALIAÇÃO DA ADIÇÃO DE ARGÔNIO À ATMOSFERA DE NITRETAÇÃO SOB PLASMA SOBRE A RESISTÊNCIA À CORROSÃO DO AÇO INOXIDÁVEL AUSTENÍTICO AISI $316 L^{*}$
}

\author{
Amanda de Angelis Vitoi ${ }^{1}$ \\ Carlos Eduardo Pinedo \\ Adonias Ribeiro Franco Júnior ${ }^{3}$
}

\section{Resumo}

Neste trabalho foi estudado o efeito da adição de argônio à atmosfera de nitretação sob plasma sobre a resistência à corrosão do aço inoxidável austenítico AISI 316L. As nitretações foram realizadas em reator a plasma pulsado, a $420^{\circ} \mathrm{C}$, por $6 \mathrm{~h}$, adicionando-se $0 \%, 5 \%$ e $10 \%$ de argônio à mistura gasosa. Os resultados mostraram que a adição de $5 \%$ de argônio promove um aumento na espessura da camada de austenita expandida em relação ao material nitretado sem argônio. Com o aumento da concentração de argônio de 5 para 10\%, no entanto, verificou-se a formação de camadas de austenita expandida mais finas e de baixa resistência à corrosão devido à presença de nitreto de cromo em sua estrutura.

Palavras-chave: Nitretação sob plasma; Aço inoxidável austenítico AISI 316L; Austenita expandida; Argônio; Corrosão.

\section{EVALUATING THE EFFECT OF ARGON ADDITION TO PLASMA NITRIDING ATMOSPHERE ON CORROSION RESISTANCE OF AISI 316L AUSTENITIC STAINLESS STEEL}

\section{Abstract}

This work aims to study the effect of argon added to plasma nitriding atmosphere on the corrosion resistance of AISI 316L austenitic stainless steel. Plasma nitriding was carried out in a pulsed plasma reactor, at $420^{\circ} \mathrm{C}$ and 6 hours, with argon additions of $0 \%, 5 \%$ and $10 \%$. The results showed that $5 \%$ argon promoted a thickening in the S-Phase layer, as compared to that layer produced without argon addition. Increasing the argon content from 5 to $10 \%$ resulted in S-Phase layer with a lower thickness and low corrosion resistance, owing to the presence of chromium nitride in its structure.

Keywords: Plasma nitriding; AISI 316L austenitic stainless steel; S-Phase; Argon; Corrosion.

1 Tecnóloga em Petróleo e Gás, Mestra em Engenharia Metalúrgica e de Materiais; Bolsista RHAE/CNPq, Heat Tech Tecnologia em Tratamento Térmico e Engenharia de Superfície Ltda., Mogi das Cruzes, SP, Brasil.

2 Engenheiro Metalurgista, Doutor em Engenharia Metalúrgica; Professor Doutor do Programa de Pós Graduação em Engenharia Metalúrgica e de Materiais, IFES, Campus Vitória, Vitória, ES, Brasil.

3 Engenheiro Metalurgista, Doutor em Ciência dos Materiais; Diretor Técnico da Heat Tech Tecnologia em Tratamento Térmico e Engenharia de Superfície Ltda., Mogi das Cruzes, SP, Brasil.

* Contribuição técnica ao $1^{\circ}$ Workshop de tratamentos de superfícies de ligas resistentes à corrosão, 21 a 25 de julho de 2014, São Paulo, SP, Brasil. 


\section{INTRODUÇÃO}

Componentes de aço inoxidável austenítico AISI $316 \mathrm{~L}$ são empregados em dispositivos e equipamentos usados em diversos segmentos industriais, em razão de sua elevada resistência à corrosão [1,2], dentre estes se destaca o segmento do petróleo e gás pelas necessidades impostas na exploração futura ao nível do présal. O aumento da resistência ao desgaste desse material pode ser obtido pelo aumento da dureza superficial mediante técnicas de tratamentos superficiais e de recobrimentos. Entre essas técnicas, os tratamentos termoquímicos de nitretação, nitrocarburação e carburação sob plasma têm sido aplicados com sucesso para atingir tal propósito, aliando uma elevação considerável da dureza superficial pela formação da austenita expandida ou Fase-S [3], sem prejuízo de resistência à corrosão [4].

O uso de temperaturas de nitretação na faixa de $380-450^{\circ} \mathrm{C}$ torna possível a obtenção de uma camada nitretada com dureza que chega a $1500 \mathrm{HV}$ e, o que é mais importante, permite manter a resistência à corrosão do aço inoxidável [5]. Sob essas condições, as superfícies nitretadas não contêm nitretos nem carbonetos complexos de cromo, e são compostas por camadas muito finas, cuja espessura ou profundidade pode variar de alguns nanômetros até mais de $10 \mu \mathrm{m}$, dependendo das condições de tempo e temperatura de nitretação empregadas [6,7]. As camadas nitretadas são constituídas por uma fase denominada na literatura Fase-S ou austenita expandida ( $\gamma \mathrm{N})$. Essa fase é uma solução sólida metaestável da austenita supersaturada em nitrogênio, possuindo estrutura cúbica de face centrada (CFC) com o parâmetro de rede expandido em relação ao da austenita ( $\mathrm{Y}$ ) que não contém nitrogênio. $O$ intersticial nitrogênio introduz grandes tensões residuais de compressão associadas à geração de defeitos de falhas de empilhamento, o que promove o endurecimento. A ausência do endurecimento resultante da precipitação de nitretos de cromo preserva a resistência à corrosão do aço inoxidável.

$\mathrm{Na}$ literatura existem poucos trabalhos que mostram a influência da adição de argônio à atmosfera gasosa usada no tratamento de nitretação a plasma de aços. Jacques e coautores [8] estudaram o efeito de diferentes misturas gasosas (nitrogênio puro, nitrogênio/hidrogênio e nitrogênio/argônio) sobre o processo de nitretação a plasma em baixas pressões para o aço ferramenta H13. Com o uso de misturas de nitrogênio/hidrogênio e nitrogênio/argônio, esses pesquisadores não verificaram mudanças significativas no crescimento das camadas nitretadas. $O$ acréscimo de hidrogênio a mistura gasosa não promoveu diferença relativa à espessura da camada em comparação a amostra nitretada com nitrogênio puro. Já a adição de argônio não só resultou em menores espessuras de camada como também em menores resistências ao desgaste em relação às amostras nitretadas em outras condições.

No presente trabalho é estudada a influência da adição de diferentes concentrações de argônio sobre a estrutura, espessura, dureza e resistência à corrosão de camadas de austenita expandida produzidas em aço inoxidável austenítico AISI $316 \mathrm{~L}$.

\footnotetext{
* Contribuição técnica ao $1^{\circ}$ Workshop de tratamentos de superfícies de ligas resistentes à corrosão, 21 a 25 de julho de 2014, São Paulo, SP, Brasil.
} 


\section{MATERIAIS E MÉTODOS}

\subsection{Aço Inoxidável Austenítico 316L}

A Tabela 1 apresenta a composição química do aço inoxidável austenítico AISI 316L, determinada em espectrômetro de emissão óptica da marca OXFORD Mod. Foundry Master Pro, pertencente ao laboratório de Caracterização de Materiais do IFES, campus Vitória. As amostras para os tratamentos superficiais foram cortadas a partir de uma barra de $32 \mathrm{~mm}$ de diâmetro e retificadas em forma de disco com aproximadamente $4 \mathrm{~mm}$ de espessura.

Tabela 1. Composição química do aço AISI 316L (\% em peso) no estado como recebido.

\begin{tabular}{cccccccc}
\hline $\mathrm{Cr}$ & $\mathrm{Ni}$ & $\mathrm{Mo}$ & $\mathrm{Mn}$ & $\mathrm{Si}$ & $\mathrm{C}$ & $\mathrm{P}$ & $\mathrm{S}$ \\
17,1 & 9,83 & 2,04 & 1,41 & 0,35 & 0,02 & 0,011 & 0,018 \\
\hline
\end{tabular}

\subsection{Nitretação sob Plasma}

Após a preparação das amostras, que envolveu as etapas de lixamento e polimento final com alumina $0,3 \mu \mathrm{m}$, os tratamentos termoquímicos de nitretação foram realizados em um reator de nitretação a plasma pulsado da marca Thor NP SDS, pertencente ao Laboratório de Engenharia de Superfícies do IFES.

Para todas as condições, a temperatura de nitretação foi fixada em $420^{\circ} \mathrm{C}$, a pressão em $533 \mathrm{~Pa}$ e o tempo de tratamento em 6 horas. As amostras foram nitretadas com e sem a adição de argônio à atmosfera de nitretação, conforme mostra a Tabela 2.

Tabela 2. Atmosferas gasosas utilizadas nos experimentos de nitretação do aço inoxidável austenítico AISI 316L.

\begin{tabular}{cc}
\hline Atmosfera 1 & $75 \% \mathrm{~N}_{2}\left(300 \mathrm{~cm}^{3} / \mathrm{min}\right)$ \\
& $25 \% \mathrm{H}_{2}\left(100 \mathrm{~cm}^{3} / \mathrm{min}\right)$ \\
\hline Atmosfera 2 & $75 \% \mathrm{~N}_{2}\left(300 \mathrm{~cm}^{3} / \mathrm{min}\right)$ \\
& $20 \% \mathrm{H}_{2}\left(80 \mathrm{~cm}^{3} / \mathrm{min}\right)$ \\
& $5 \% \operatorname{Ar}\left(20 \mathrm{~cm}^{3} / \mathrm{min}\right)$ \\
\hline Atmosfera 3 & $75 \% \mathrm{~N}_{2}\left(300 \mathrm{~cm}^{3} / \mathrm{min}\right)$ \\
& $15 \% \mathrm{H}_{2}\left(60 \mathrm{~cm}^{3} / \mathrm{min}\right)$ \\
& $10 \% \mathrm{Ar}\left(40 \mathrm{~cm}^{3} / \mathrm{min}\right)$ \\
\hline
\end{tabular}

A remoção do filme passivo foi realizada previamente aos tratamentos de nitretação, por bombardeamento iônico, "sputtering cleaning", sob plasma de hidrogênio utilizando; pressão de $100 \mathrm{~Pa}$, fluxo de hidrogênio de $200 \mathrm{~cm}^{3} / \mathrm{min}$ durante cerca de 20 minutos, na temperatura de $x_{x x}^{\circ} \mathrm{C}$.

\subsection{Caracterização das Camadas Nitretadas}

$\mathrm{O}$ ataque químico para revelação microestrutural foi feito por imersão, durante 60 segundos, utilizando uma solução de $\mathrm{HCl}, \mathrm{HNO}_{3}$ e $\mathrm{H}_{2} \mathrm{O}$, na proporção de 2:1:1. As

* Contribuição técnica ao $1^{\circ}$ Workshop de tratamentos de superfícies de ligas resistentes à corrosão, 21 a 25 de julho de 2014, São Paulo, SP, Brasil. 
análises microestruturais foram realizadas em microscópio óptico dotado de analisador de imagens ASM 68K - WILD LEITZ, pertencente ao laboratório de Corrosão do IFES. A identificação das fases presentes na superfície foi feita por Difração de Raios X, em equipamento D2 PHASER - Bruker, pertencente ao Laboratório de Caracterização do IFES, utilizando simetria de Bragg-Brentano, com intervalo de varredura de $2 \theta$ entre $30^{\circ}$ e $100^{\circ}$ e radiação de $\mathrm{Cu}-\alpha$ com comprimento de onda $\lambda=1,5406 \AA$.

As camadas nitretadas obtidas possuíam uma pequena espessura, o que impossibilitou realizar perfis de dureza. No entanto, foram realizadas durezas de topo com indentador Vickers utilizando-se cargas 200 gramas.

Os ensaios eletroquímicos de corrosão foram realizados em um potenciostato/galvanostato AUTOLAB PGSTAT 302N, pertencente ao laboratório de Eletroquímica e Eletroanálise da UFES. As técnicas eletroquímicas utilizadas foram: curvas de polarização, curvas de Tafel e espectroscopia de impedância eletroquímica (EIE). O meio corrosivo foi composto por uma solução de cloreto de sódio $(\mathrm{NaCl})$ a 150.000 ppm. Os eletrodos auxiliares utilizados foram o eletrodo de grafite, com área de $3,0 \mathrm{~cm}^{2}$ e o eletrodo de referência prata-cloreto de prata $(\mathrm{Ag} / \mathrm{AgCl} / \mathrm{KCl})$ saturado, Figura 1.

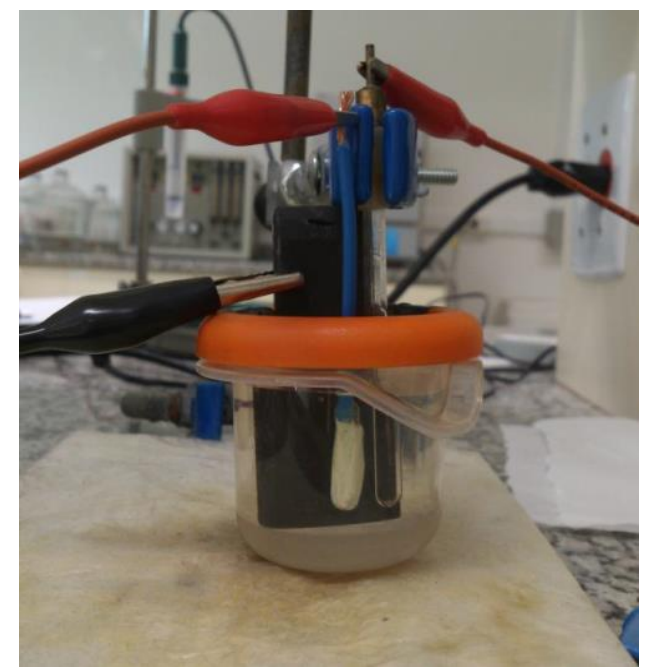

Figura 1. Célula eletroquímica utilizada nos ensaios de corrosão.

\section{RESULTADOS E DISCUSSÃO}

\subsection{Espessura e Estrutura das Camadas Nitretadas}

A Figura 2 mostra detalhes da espessura e estrutura das camadas nitretadas obtidas com o uso de atmosferas de nitretação contendo adições de argônio de 0\%, 5\% e $10 \%$.Verifica-se que a adição de argônio à atmosfera de nitretação levou à formação de camadas nitretadas de diferentes espessuras. $O$ aço nitretado com $5 \%$ de argônio, Figura 2(b), apresenta uma maior espessura de camada nitretada em relação ao aço nitretado sem argônio (0\%), Figura 2(a). O aumento na espessura da camada nitretada com 5\% de Ar pode ser inferido ao aumento na energia de bombardeamento iônico decorrente da introdução do argônio, causando, com isso, um aumento na densidade dos defeitos cristalinos superficial, em particular de lacunas, intensificando a incorporação de nitrogênio na camada limite "plasma/sólido metálico" e elevando a difusão dos átomos de nitrogênio a partir da superfície.

* Contribuição técnica ao $1^{\circ}$ Workshop de tratamentos de superfícies de ligas resistentes à corrosão, 21 a 25 de julho de 2014, São Paulo, SP, Brasil. 

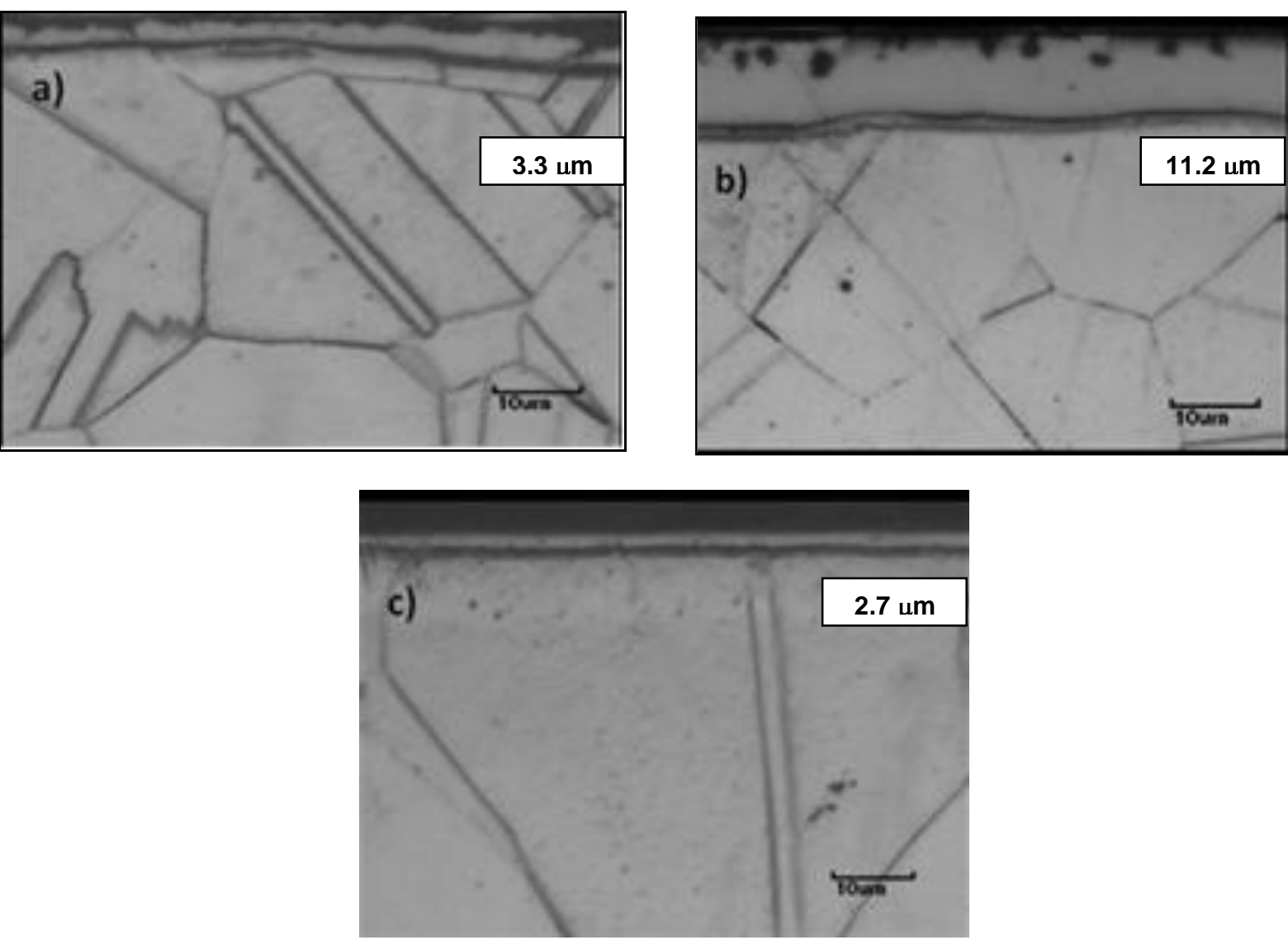

Figura 2. Detalhes das camadas nitretadas obtidas na superfície do aço inoxidável austenítico AISI $316 \mathrm{~L}$ após nitretação usando atmosferas contendo: (a) 0\%, (b) 5\% e (c) $10 \%$ de argônio.

O mesmo não aconteceu com a adição de $10 \%$ de $\operatorname{Ar}$, pois se nota a formação de uma camada nitretada mais fina, Figura 2(c). Nesta condição, os autores inferem que o excesso de lacunas e o consequente excesso de nitrogênio na interface de nitretação possibilitaram o processo de precipitação de nitreto de cromo e com isso, a necessidade de difusão do substitucional $(\mathrm{Cr})$, conforme previsto no modelo de Jack $[9,10]$ e confirmado em ligas martensíticas [11], ocorreu uma diminuição na velocidade de deslocamento da interface de nitretação e, por consequência, da cinética global do processo. Com isso, uma menor quantidade de nitrogênio ficou disponível para se difundir em direção ao núcleo e o crescimento da camada de austenita expandida foi menor.

A Figura 3 compara o Difratograma deRaios-X (DRX) do aço não nitretada com os do aço nitretado com $0 \%, 5 \%$ e $10 \%$ de argônio. Para todas as condições de nitretação estudadas observa-se que os picos da austenita expandida se deslocaram para ângulos de difração $2 \theta$ menores que os da austenita $(\mathrm{y})$. Esse comportamento se deve à introdução de uma grande quantidade de nitrogênio na austenita, que pode atingir $40 \%$ at. e causar uma expansão de até $9,5 \%$ no parâmetro de rede da austenita [12,13]. A supersaturação intersticial em nitrogênio gera distorções elásticas no reticulado cristalino, cujo efeito é o alargamento dos picos difratados [14], o que vem confirmar a formação da austenita expandida ( $\mathrm{YN}$ ) em todos as condições de nitretação estudadas neste trabalho.

No difratograma do aço nitretado com $10 \%$ Ar, verifica-se, além do pico de austenita expandida, a presença de nitreto de cromo do tipo CrN. Este resultado vai de encontro à discussão anterior, na qual a adição de $10 \%$ de argônio causa excesso de defeitos pontuais, eleva a incorporação e a difusão de nitrogênio, gerando as

* Contribuição técnica ao $1^{\circ}$ Workshop de tratamentos de superfícies de ligas resistentes à corrosão, 21 a 25 de julho de 2014, São Paulo, SP, Brasil. 
condições termodinâmicas e cinéticas necessárias para a precipitação dos nitretos de cromo.

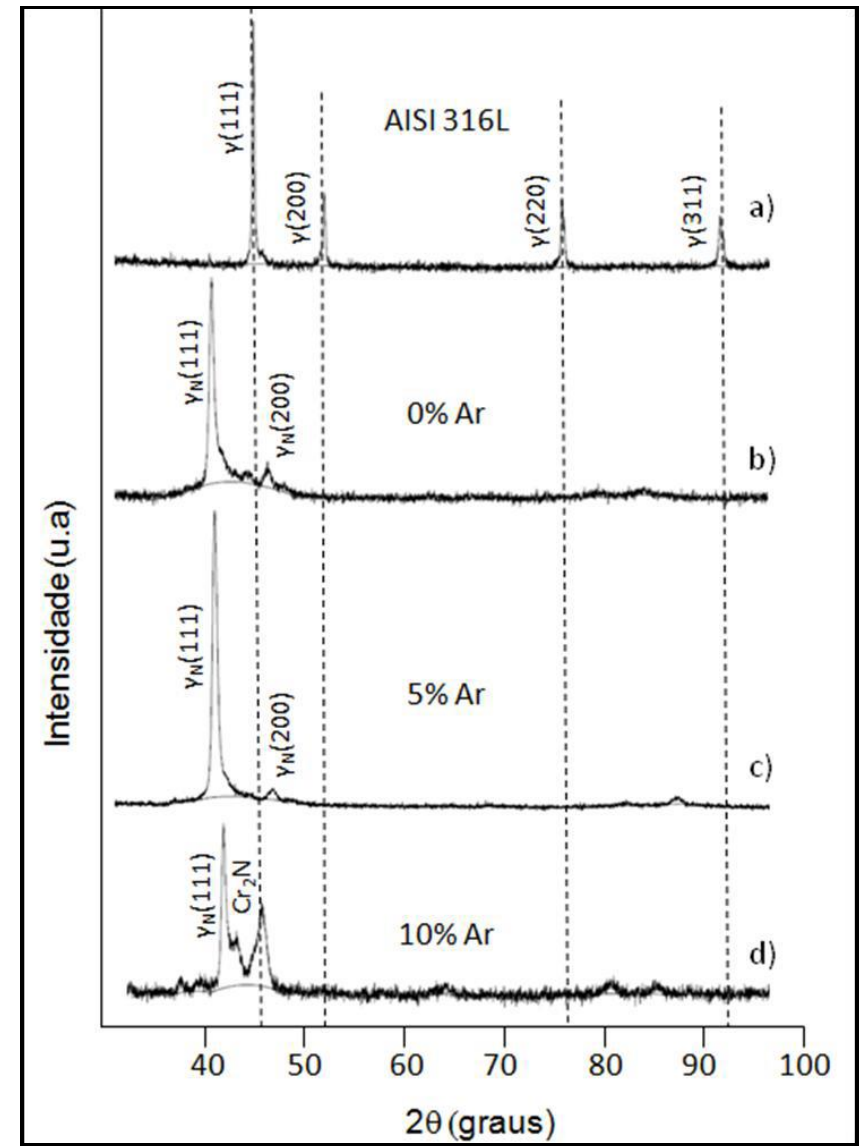

Figura 3. Difratogramas de raios $X$ das amostras de aço inoxidável austenítico AISI 316L nitretadas.

\subsection{Endurecimento}

A Figura 4 apresenta a relação das medidas de microdureza com a concentração de argônio presente na atmosfera de nitretação. Em relação à matriz, todas as amostras nitretadas apresentaram um aumento significativo da dureza superficial. Esse aumento se deve à formação de camada de austenita expandida que conforme mostrado na Figura 2 apresentou espessuras na faixa de 2,7 a 11,3 $\mu \mathrm{m}$. A dureza superficial dos aços nitretados chega a ser 5 vezes maior que a do material não nitretado. A amostra sem adição de argônio apresentou a maior dureza (1430 HV). A queda na dureza do material nitretado com 10\% Ar pode estar relacionada ao empobrecimento de cromo da camada e consequente formação de nitreto de cromo identificado conforme mostrado na Figura 3(d).

* Contribuição técnica ao $1^{\circ}$ Workshop de tratamentos de superfícies de ligas resistentes à corrosão, 21 a 25 de julho de 2014, São Paulo, SP, Brasil. 

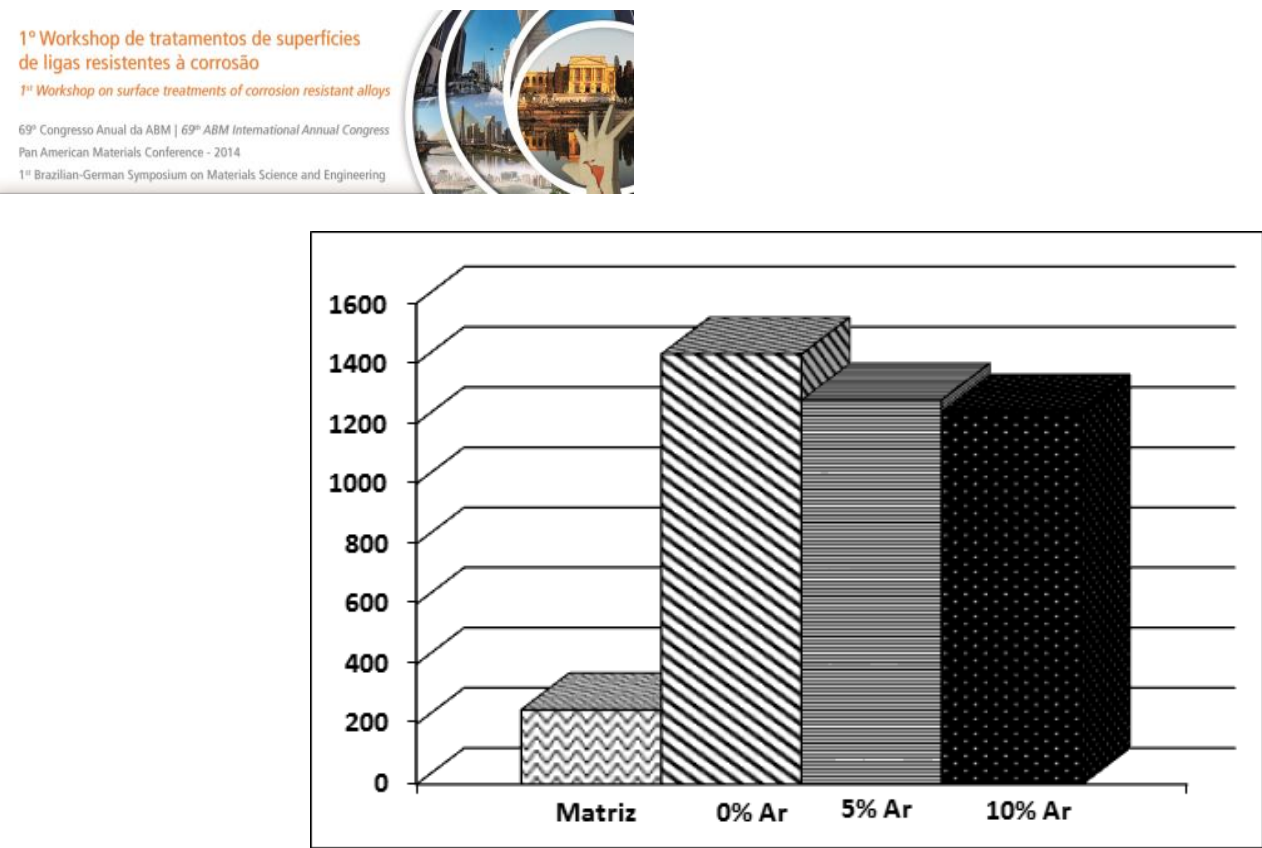

Figura 4. Variação da dureza superficial das camadas nitretadas do aço inoxidável 316L em função da concentração de argônio usada na atmosfera de nitretação.

\subsection{Resistência à Corrosão}

\subsubsection{Curvas de Tafel}

Para o aço inoxidável AISI 316L antes e após a nitretação, a Figura 5 apresenta as curvas de Tafel obtidas em íons cloreto $\left(\mathrm{Cl}^{-}\right)$. Verifica-se que o maior valor de potencial de corrosão Ec é apresentado pela amostra tratada em atmosfera contendo $5 \%$. Isso indica que a camada possui maior dificuldade em sofrer corrosão, de acordo com a equação de Nernst:

$$
E=E^{0}-\frac{R T}{n F} \ln Q \rightarrow \Delta E=-\frac{R T}{n F} \ln Q
$$

onde $\Delta \mathbf{E}$ representa o potencial de corrosão, $\mathbf{R}$ é a constante universal dos gases, $\mathbf{T}$ é a temperatura, $\boldsymbol{n}$ é o número de elétrons transferidos e $\ln \boldsymbol{Q}$ é o quociente da reação.

O aumento na formação de produtos de corrosão (termo InQ da Equação 1) implica em potenciais mais negativos. Dessa forma, a amostra nitretada com $5 \%$ de argônio apresentou um maior potencial de corrosão em comparação não só à amostra não nitretada (matriz) como também às nitretadas com $0 \% \operatorname{Ar}$ e 10\%. Como a camada nitretada obtida usando $5 \% \mathrm{Ar}$ apresenta-se livre de nitreto de cromo, conforme análise DRX mostrada na Figura 3(c), e possui a maior espessura, conforme mostrada a Figura 2(c), possivelmente houve uma maior dificuldade dos íons em atingir o substrato, exigindo a aplicação de um maior potencial.

* Contribuição técnica ao $1^{\circ}$ Workshop de tratamentos de superfícies de ligas resistentes à corrosão, 21 a 25 de julho de 2014, São Paulo, SP, Brasil. 


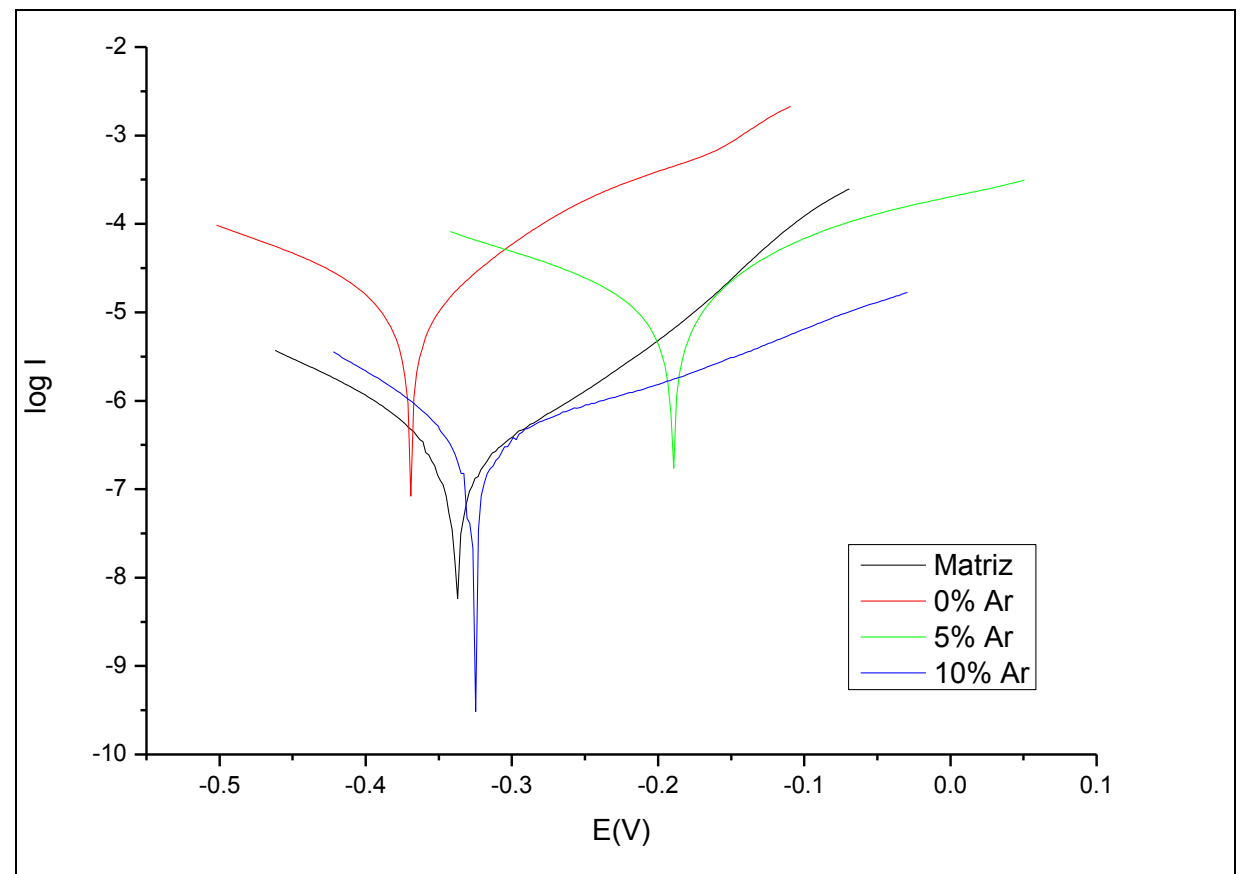

Figura 5. Curvas de Tafel em íons cloreto para o aço 316L não nitretado e nitretado a plasma em diferentes atmosferas gasosas.

\subsubsection{Extrapolação de Tafel}

A partir dos parâmetros de Tafel foi possível obter os valores do potencial de corrosão, confirmando que a amostra nitretada com $5 \%$ de $\mathrm{Ar}$ apresenta potencial de corrosão mais positivo $(-0,19 \mathrm{~V})$. No entanto, essa amostra taxa de corrosão depende da Icorr e da resistência de polarização, as quais são medidas a partir do Ecorr. A amostra que apresenta a menor taxa de corrosão é a nitretada com $10 \%$ de Ar. A Tabela 3 apresenta as análises feitas a partir da extrapolação de Tafel.

Tabela 3. Parâmetros de Tafel em solução contendo íons cloreto para o aço inoxidável não nitretado e nitretado sob diferentes atmosferas de nitretação.

\begin{tabular}{cccccc}
\hline Solução & Amostra & $\operatorname{Icorr}(\mathbf{A}) \mathbf{x} \mathbf{1 0}^{-6}$ & $\mathbf{R p}(\boldsymbol{\Omega}) \times 10^{4}$ & Ecorr $(\mathbf{V})$ & $\begin{array}{c}\text { Taxa corrosão } \\
(\mathbf{m m} / \mathbf{a n o}) \mathbf{x 1 0 ^ { - 2 }}\end{array}$ \\
\hline \multirow{3}{*}{$\mathbf{C l}^{-}$} & Matriz & 0,07 & 9,94 & $-0,34$ & 0,08 \\
& $0 \% \mathrm{Ar}$ & 4,71 & 0,20 & $-0,37$ & 4,91 \\
& $5 \% \mathrm{Ar}$ & 8,92 & 0,22 & $-0,19$ & 9,30 \\
& $10 \% \mathrm{Ar}$ & 0,05 & 3,31 & $-0,32$ & 0,06 \\
\hline
\end{tabular}

A corrente de corrosão (icorr), importante parâmetro de análise da resistência à corrosão, depende da reação de corrosão (transferência de massa) que ocorre durante a dissolução do metal. Essa corrente se relaciona com a massa de metal dissolvida (Lei de Faraday) da seguinte forma:

$$
i_{\text {cort }}=\frac{n F m}{M}
$$

onde, icorr é a corrente de corrosão (A), t é o tempo (s) que a corrente flui, $\mathbf{n}$ é o número de elétrons envolvidos na dissolução metálica e $\mathbf{F}$ é a constante de Faraday ( $F=96500 C$ ), $m$ é a massa $(g)$ do metal que sofreu dissolução e M é peso molecular (g) do metal. Nota: nF é o número de Coulombs necessário para converter $1 \mathrm{~mol}$ do metal em produtos de corrosão.

Da equação 2 pode-se inferir que a corrente de corrosão é proporcional à massa do metal corroído, ou seja, quanto maior a corrente de corrosão maior será a

* Contribuição técnica ao $1^{\circ}$ Workshop de tratamentos de superfícies de ligas resistentes à corrosão, 21 a 25 de julho de 2014, São Paulo, SP, Brasil. 


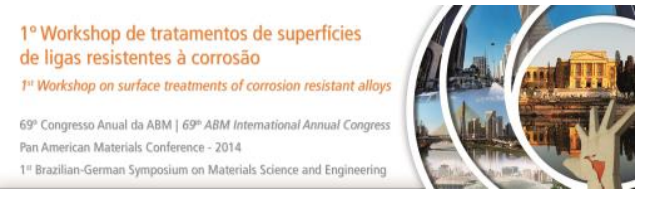

quantidade de massa de metal corroído. Analisando a Tabela 3, verifica-se que a amostra não nitretada possui a menor corrente de corrosão, o que permite concluir que a amostra não nitretada apresentou nos ensaios a menor perda de massa.

A resistência à polarização $(R p)$ é proporcional à variação do potencial elétrico/variação de corrente elétrica do sistema (ASTM G-59, 1997). De acordo com Gu e colaboradores [15], um baixo valor de Rp indica um alto potencial de corrosão e um valor alto indica que o material não é suscetível à corrosão. Na Tabela 3 é possível verificar que a amostra não nitretada é a que apresenta a menor suscetibilidade à corrosão em solução de $\mathrm{NaCl}$, apresentando $R_{p}=9,94 \times 10^{4} \Omega$. Provavelmente, isso ocorreu pelo fato do material não nitretado apresentar uma superfície mais homogênea, o que dificulta a penetração do eletrólito em sua superfície. Nas amostras nitretadas, a queda na resistência de polarização verificada pode estar associada a irregularidades geradas na superfície do material, as quais facilitam a penetração do eletrólito.

\subsubsection{Espectroscopia de impedância eletroquímica (EIE)}

A Figura 6 apresenta o diagrama de Nyquist em solução contendo íons cloreto para o aço inoxidável 316L nitretado usando diferentes concentrações de argônio. Os valores de freqüência mostrados indicam a ocorrência do ponto de máximo do primeiro arco capacitivo formado.

$\mathrm{Na}$ Figura 6(a) verifica-se a formação de apenas um arco capacitivo tanto para o aço não nitretado quanto para o nitretado com 10\% de argônio. A Figura 6(b), no entanto, mostra a formação de dois arcos capacitivos para a amostra nitretada com $5 \%$ Ar. O primeiro arco sugere a atividade da camada nitretada com o eletrólito, enquanto o segundo arco sugere a atividade do substrato com 0 eletrólito. Possivelmente, a alta atividade dessa camada com o eletrólito se deve a sua maior espessura.

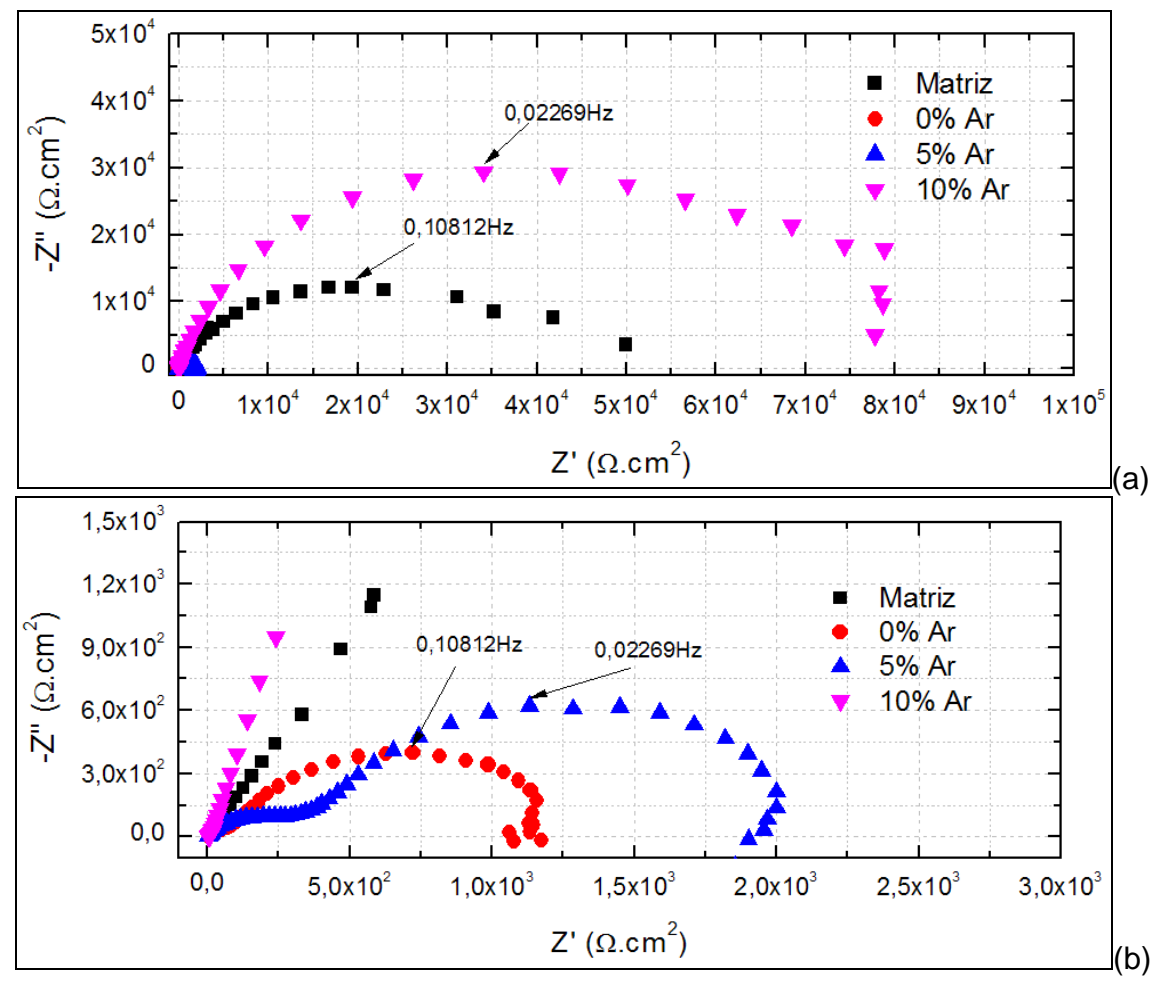

Figura 61. (a) Diagrama de Nyquist em solução contendo íons cloreto, para o aço AISI não nitretado e nitretado sob diferentes concentrações de argônio; ("b) Ampliação da região de baixos valores de Z" $x Z^{\prime}$.

* Contribuição técnica ao $1^{\circ}$ Workshop de tratamentos de superfícies de ligas resistentes à corrosão, 21 a 25 de julho de 2014, São Paulo, SP, Brasil. 
A Tabela 4 apresenta os valores das resistências de polarização obtidos através do arco capacitivo.

Tabela 4. Resistência de polarização em razão das condições não nitretadas e nitretadas.

\begin{tabular}{ccc}
\hline Eletrólito & AISI 316l & $\mathrm{R}_{\mathrm{p}}(\Omega)$ \\
\hline & Não nitretado & 19370 \\
$\mathrm{Cl}^{-}$ & $0 \% \mathrm{Ar}$ & 723 \\
& $5 \% \mathrm{Ar}$ & 3401 \\
& $10 \% \mathrm{Ar}$ & 1133 \\
\hline
\end{tabular}

Analisando os resultados de resistência de polarização $\left(R_{P}\right)$, observa-se que em relação ao aço não nitretado todos os aços nitretados apresentaram uma queda na sua resistência de polarização (Rp). A menor queda em $R_{P}$ é apresentada pelo aço que possui a maior espessura de camada, ou seja, o aço nitretado em atmosfera contendo $5 \%$ de argônio.

Para o aço nitretado em atmosfera de $0 \% \mathrm{Ar}$, a queda no valor da resistência de polarização pode estar associada à baixa espessura da camada nitretada produzida. Quando se usam atmosferas de nitretação contendo $10 \% \mathrm{Ar}$, a camada nitretada resultante apresenta uma espessura muito mais fina $(2,7 \mu \mathrm{m})$, e provavelmente, possui uma superfície mais rugosa, o que favorece a queda da resistência de polarização. A presença de nitreto de cromo foi evidenciada somente na superfície dessa amostra, conforme mostrado na Figura 3(d). Portanto, conclui-se que o uso de misturas gasosas contendo altas concentrações de argônio pode levar à formação de camadas de austenita expandida de baixa espessura, contendo nitreto de cromo e de baixa resistência à polarização.

\section{CONCLUSÃO}

Os resultados obtidos permitem concluir que:

- Todas as condições de nitretação estudadas neste trabalho proporcionam um aumento significativo na dureza superficial do aço inoxidável austenítico AISI 316L. O aumento na dureza superficial se deve à camada de austenita expandida $(\mathrm{YN})$ formada na superfície do material.

- A adição de 5\% argônio à atmosfera de nitretação propicia um aumento significativo na espessura da camada de austenita expandida $(11,2 \mu \mathrm{m})$, que apresenta o maior potencial de corrosão $(-0,19 \mathrm{~V})$. A dificuldade dos íons cloreto em atingir 0 substrato possivelmente está relacionada ao desenvolvimento de uma camada mais espessa.

- O aço não nitretado apresenta uma maior resistência à polarização. Isso possivelmente se deve à formação de uma camada de baixa rugosidade superficial, o que dificulta a penetração do eletrólito.

- O aumento da concentração de argônio para $10 \%$ promove a formação de uma camada de austenita expandida de baixa espessura, contendo nitreto de cromo em sua estrutura e, em conseqüência, piora a resistência à corrosão do material.

\section{Agradecimentos}

Os autores agradecem ao CNPq, Edital Universal 2010, pelo apoio financeiro. A primeira autora agradece a CAPES pela bolsa de mestrado concedida.

* Contribuição técnica ao $1^{\circ}$ Workshop de tratamentos de superfícies de ligas resistentes à corrosão, 21 a 25 de julho de 2014, São Paulo, SP, Brasil. 


\section{REFERÊNCIAS}

1 Leyland $A$, Matthews $A$. On the significance of $H / E$ ratio in wear control: a nanocomposite coating approach to optimised tribological behaviour. Wear. 2000;246(12):1-11.

2 Bell T. Surface engineering of austenitic stainless steel. Surface Engineering. 2002;18(6):415-421.

3 Pinedo CE, Tschiptschin AP. Low temperature nitriding, nitrocarburizing and carburizing of AISI 316L austenitic stainless steel. International Heat Treatment and Surface Engineering. 2011;5;73-77.

4 Liang W, Bin X, Zhiwei Y, Yaqin S. The wear and corrosion properties of stainless steel nitrided by low-pressure plasma-arc source ion nitriding at low temperatures. Surface and Coatings Technology. 2000;130(2-3):304-308.

5 Tschiptschin AP, Pinedo CE. Estrutura e propriedades do aço inoxidável austenítico AISI 316L Grau ASTM F138 nitretado sob plasma à baixa temperatura. REM: R. Esc. Minas. 2010;63(1):137-141.

6 Borgioli F, Fossati A, Galvanetto E, Bacci T. Glow-discharge nitriding of AISI 316L austenitic stainless steel: influence of treatment temperature. Surface and Coatings Technology. 2005;200(7):2474-2480.

7 Fossati A, Borgioli F, Galvanetto E, Bacci T. Glow-discharge nitriding of AISI 316L austenitic stainless steel: influence of treatment time. Surface and Coatings Technology. 2006;200(11):3511-3517.

8 Jacques RC, Reguly A. Caracterização de amostras de $\mathrm{H} 13$ nitretadas a baixas pressões com diferentes misturas gasosas. Tecnol. Metal. Mater. Miner. 2010;6(4):201205.

9 Jack DH. Nitriding. In: Heat Treatment'73. 1973: 39-50.

10 Lightfoot J, Jack DH. Kinetics of nitriding with and without compound layer formation. In: Heat Treatment'73. 1973: 59-65.

11 Pinedo CE, Monteiro WA. On the kinetics of plasma nitriding a martensitic stainless steel type AISI 420. Surface and Coatings Technology. 2004;179:119-123.

12 Blawert C, Weisheit A, Mordike BL, Knoop RM. Plasma immersion ion implantation of stainless steel: austenitic stainless steel in comparison to austenitic-ferritic stainless steel. Surface and Coatings Technology. 1996;85(1):15-27.

13 Fewell MP, Mitchell DRG, Priest JM, Short KT, Collins GA. The nature of expanded austenite. Surface and Coatings Technology. 2000;131(1):300-306.

14 Fernandes FAP, Pereira RG, Casteletti LC, Gallego J. Análise cristalográfica da austenita expandida em aços inoxidáveis. In: Anais do 66 Congresso Anual da ABM; 2011; São Paulo, Brasil. São Paulo: ABM; 2011. p.565-575.

15 Gu P, Arsenault B, Beaudoin JJ, Legoux JG, Harvey B, Fournier J. Polarization resistance of stainless steel-coated rebars. Cemented and concrete Research. $1998 ; 28(3): 321-327$.

* Contribuição técnica ao $1^{\circ}$ Workshop de tratamentos de superfícies de ligas resistentes à corrosão, 21 a 25 de julho de 2014, São Paulo, SP, Brasil. 